\title{
A Conceptual Design Activity for a First-year Mechanical Engineering Course
}

\section{Dr. Oziel Rios, University of Texas, Dallas}

Dr. Oziel Rios earned his Ph.D. in mechanical engineering from the University of Texas at Austin in 2008 where his research focused on design of robotic systems with an emphasis on kinematic and dynamic modeling for analysis and control. Dr. Rios teaches the first-year and CAD courses in the Mechanical Engineering Department at the University of Texas at Dallas. Dr. Rios has also taught kinematics and dynamics of machines and graduate-level CAD courses. Dr. Rios' research and teaching interests include: robotics, design, kinematics and dynamics of machines and engineering education.

\section{Dr. Dani Fadda, University of Texas, Dallas}

Dr. Fadda is Clinical Associate Professor of Mechanical Engineering. His background includes two decades of professional engineering practice in the energy industry where he has held numerous positions. Dr. Fadda has worked in product research and developed patented products for chemical, petrochemical, and nuclear applications. He is involved with professional organizations and was named the 2016 ASME North Texas Engineer of the Year. 


\title{
A Conceptual Design Activity for a First-Year Mechanical Engineering Course
}

\begin{abstract}
In this evidence-based paper, an activity is described where students develop and validate conceptual designs of a gear train mechanism composed of spur gears. The design and operation of motion and power transmission systems is an important topic of study for mechanical engineering students. This topic is usually most closely associated with the mechanical engineering profession and may be addressed in a first-year course by describing the need for such systems and investigating equations of simple systems. In the activity described in this paper, students analyze the system, search for components from a catalog, and validate their design by building 3D computer models and running kinematic simulations on CAD software. The activity was successfully administered to an introduction to mechanical engineering class of 221 students during the Spring semester of 2017. A discussion of the resources and personnel required (faculty and graduate teaching assistants) is also presented. The activity is considered simple to implement only requiring a computer station with installed CAD software offered by most engineering programs. Continuous improvements to the activity are made based on faculty observations as well as a survey administered to the students.
\end{abstract}

\section{Introduction}

Incorporating team-based design projects into first-year engineering courses is beneficial to firstyear engineering students [1]. First-year design projects have been proven to increase motivation [2-5] and improve retention [6]. At our university, students take a two-course sequence of introduction to mechanical engineering courses. The first course is a 1 credit-hour course taken in the Fall semester where students work on team-based, hands-on activities related to design methodology, graphical communication, project management, use of numerical analysis software, and ethics. The second course is a 2 credit-hour course typically taken in the Spring semester [7]. While the first course focuses on topics of relevance to all engineering majors, the second course focuses on design-related activities relevant to the mechanical engineering profession and covering the topics of CAD [8], forces on structures [9], thermal energy and fluid systems [10], and mechanical components [11].

In the Fall 2016 semester, 198 students took the first semester, 1 credit-hour course. Considering the Spring, Summer, and Fall 2017 semesters, 161 students who took the first course, completed the second, 2 credit-hour course yielding a retention of rate of $81 \%$ for these first-year courses. This is comparable with the observations of retention rates presented by Knight, et al., for firstyear courses implementing hands-on, team-based projects [6]. As indicated by Ambrose and Amon, engaging students with hands-on projects is vital for first-year engineering courses and it is fundamental in our course as well [2]. Another tenet of first-year engineering courses proposed by Ambrose and Amon is providing "frequent, prompt and constructive feedback" [2]. This is achieved in our course by offering smaller lab sections wherein the faculty, Graduate Teaching Assistants (GTAs), and upper-level Undergraduate Student (UGS) helpers provide immediate feedback to students as they are working on their projects. This will be described in more detail in Section 3. 
The project described in this paper deals with the design and operation of motion and power transmission systems which is an important topic of study for mechanical engineering students. This topic is usually most closely associated with the mechanical engineering profession and is addressed in the first-year course by describing the need for such systems and investigating kinematic equations of gear trains composed of simple and compound spur gears [12]. For the conceptual design activity, students are given the functional requirements for the mechanism and design constraints. They are asked to select spur gears from an online catalog to achieve the requirement. The students are directed to download 3D CAD models of the gears from the online catalog, build a 3D assembly model of their design, and run kinematic simulation to ensure their design satisfies the functional requirement and constraints.

In the rest of this paper, a more detailed description of the activity is provided as well as observations of the activity.

\section{Description of Project}

Our objective when creating this activity was to provide a valuable learning experience to achieve the course learning outcomes while providing an engaging and enjoyable experience for the students.

An example of the mechanism the students were asked to design is shown in Figure 1. This type of mechanism can be applied to milling machines, loading trays of Blu-ray players, and other applications. The conceptual design activity consisted of selecting four spur gears and a rack to achieve an output linear speed of $0.25 \mathrm{in} / \mathrm{sec}$ (speed of the rack). An allowable range for the input motor speed was given. Students were asked to select from plastic molded gears available in the McMaster-Carr online catalog [13] to achieve the required output linear speed.

As an incentive to be mindful of costs, teams with the lowest cost for the gears were awarded bonus points. However, optimizing the design for achieving the lowest cost was not a requirement.

The kinematic equations for this mechanism are straightforward. Let $r_{i}$ and $\omega_{i}$ be the pitch radius and angular speed, respectively, of gear i (where $\mathrm{i}$ is $1,2,3$, or 4 ), let $v_{5}$ be the speed of the rack gear 5 (the output speed). The velocity ratio of the mechanism is determined to be

$$
\frac{v_{5}}{\omega_{1}}=\frac{r_{1} r_{3}}{r_{2}}
$$

where $\omega_{1}$ is the input speed. In order to derive this equation and properly apply it, students had to understand the following concepts [12].

- Angular speed and implementing the appropriate units (revolutions per minute vs. radians per second).

- The fundamental property of gearsets achieved with the involute tooth profile.

- $\quad$ Pitch radius/diameter and selecting diametral pitch to ensure gearsets mesh. 
- Simple and compound gearsets for motion transmission.

- Velocity ratios and idler gears.

Students had to use this equation to search the catalog for a set of gears that satisfy the requirements and constraints. The search is greatly simplified if students realize gear 4 is an idler gear and $r_{1}<r_{2}$ for speed reduction.

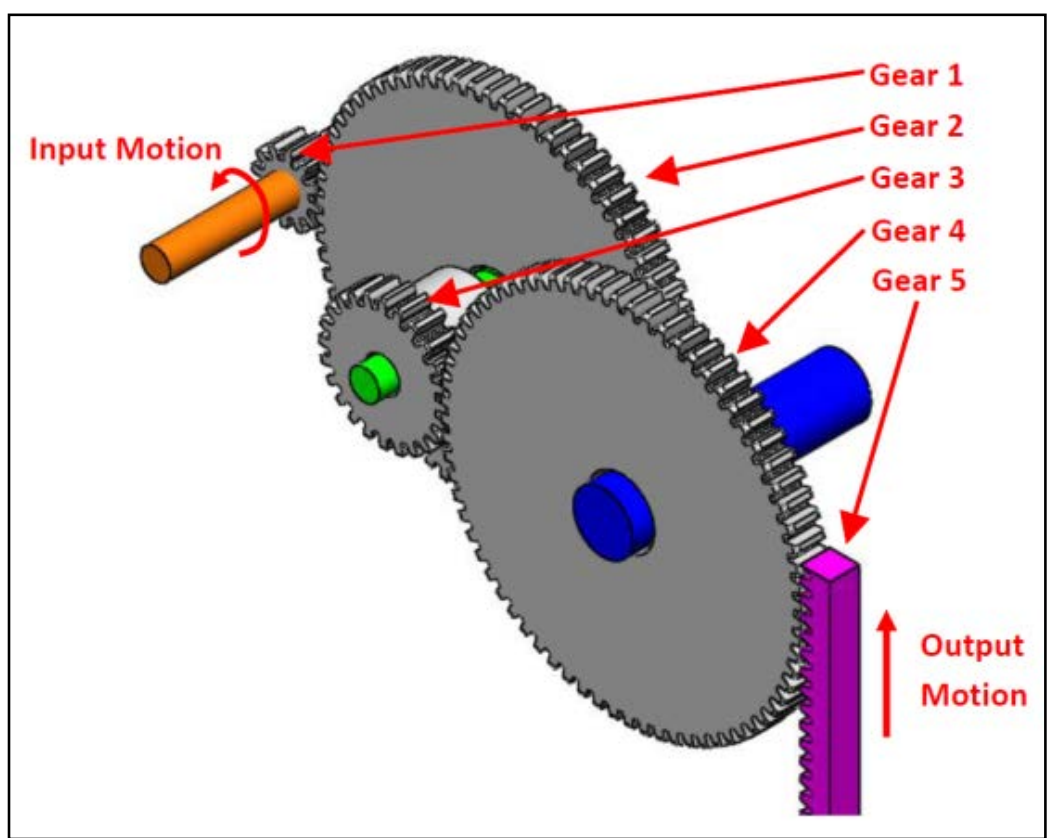

Figure 1. Mechanism composed of spur and rack gears. Gears 2 and 3 form a compound gear.

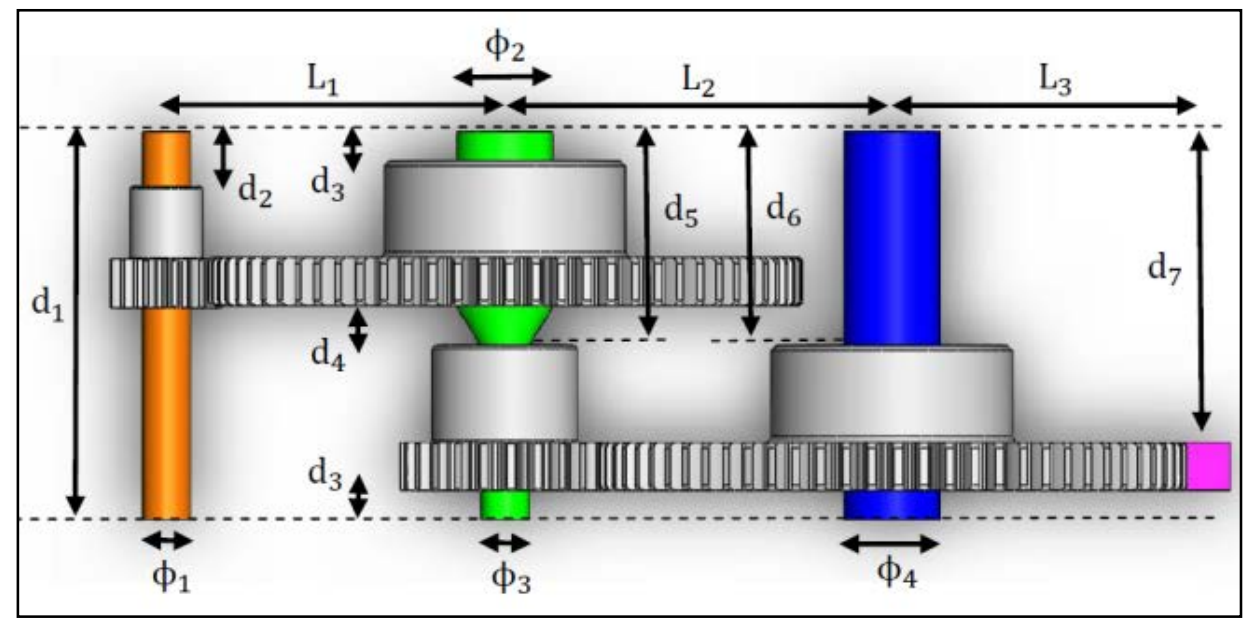

Figure 2. Top view of the mechanism showing the parameters needed for the 3D assembly model.

Once the gears were selected, students downloaded 3D models of the spur and rack gears to create a 3D assembly model. Although the mechanism looks simple, many parameters must be determined before the 3D assembly model could be created (see Figure 2). Some of the 
parameters need to be selected or determined by the students while others are based on their gear selections. The values of $L_{1}, L_{2}$ and $L_{3}$ are determined based on the pitch diameters of the gears. The value of $d_{1}$ (the shaft length) is selected to ensure that there is enough clearance in the shaft after the gears are assembled. The values of $d_{2}, d_{3}, d_{4}, d_{5}, d_{6}$ and $d_{7}$ are based on the overall width of the selected gears and to ensure that the gears mate. The values of $\phi_{1}, \phi_{2}, \phi_{3}$ and $\phi_{4}$ are based on the bore diameters of the selected gears. Based on these parameters, the students had to create 3D models of the shafts.

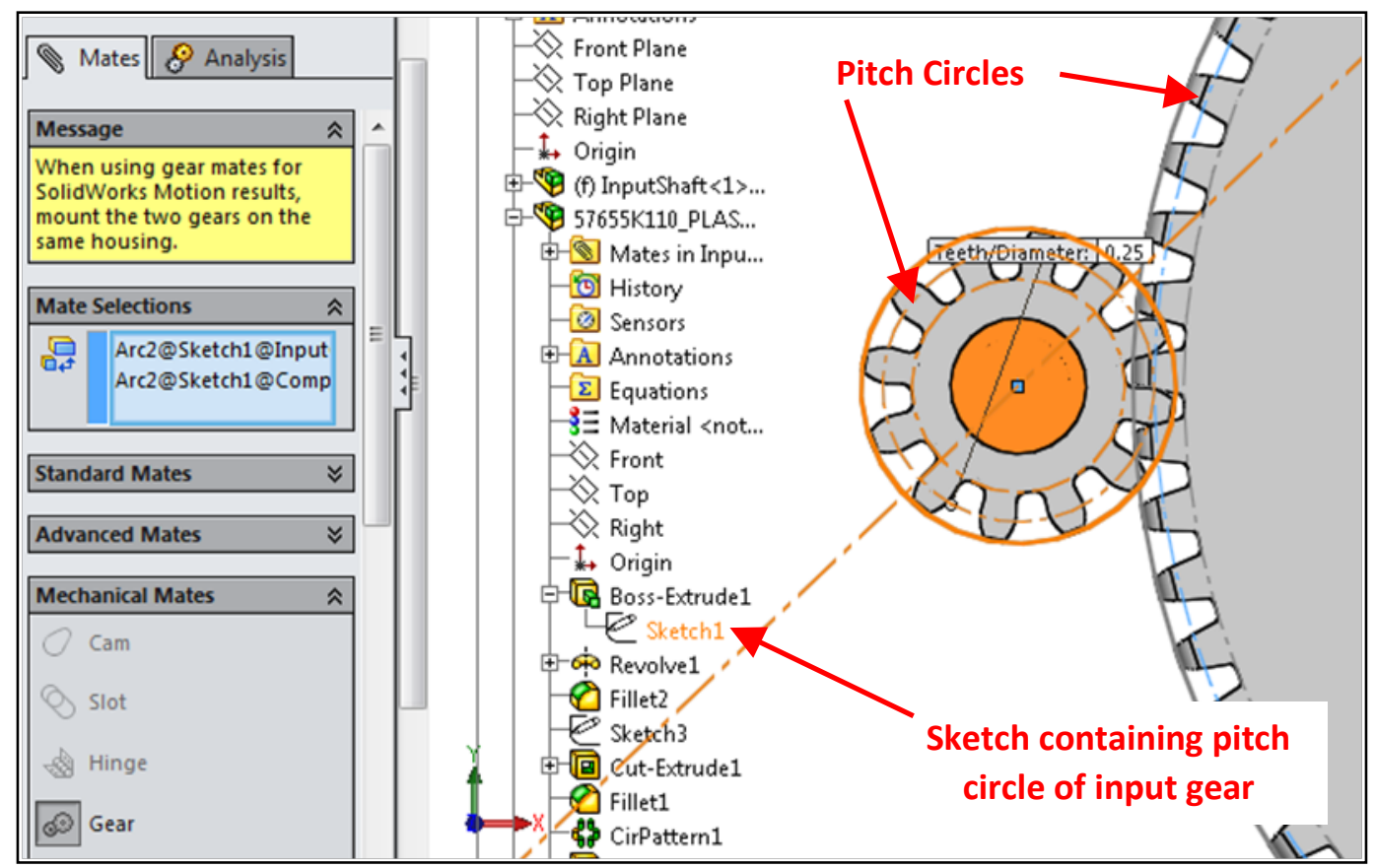

Figure 3. Using pitch circles to define gear mate constraint.

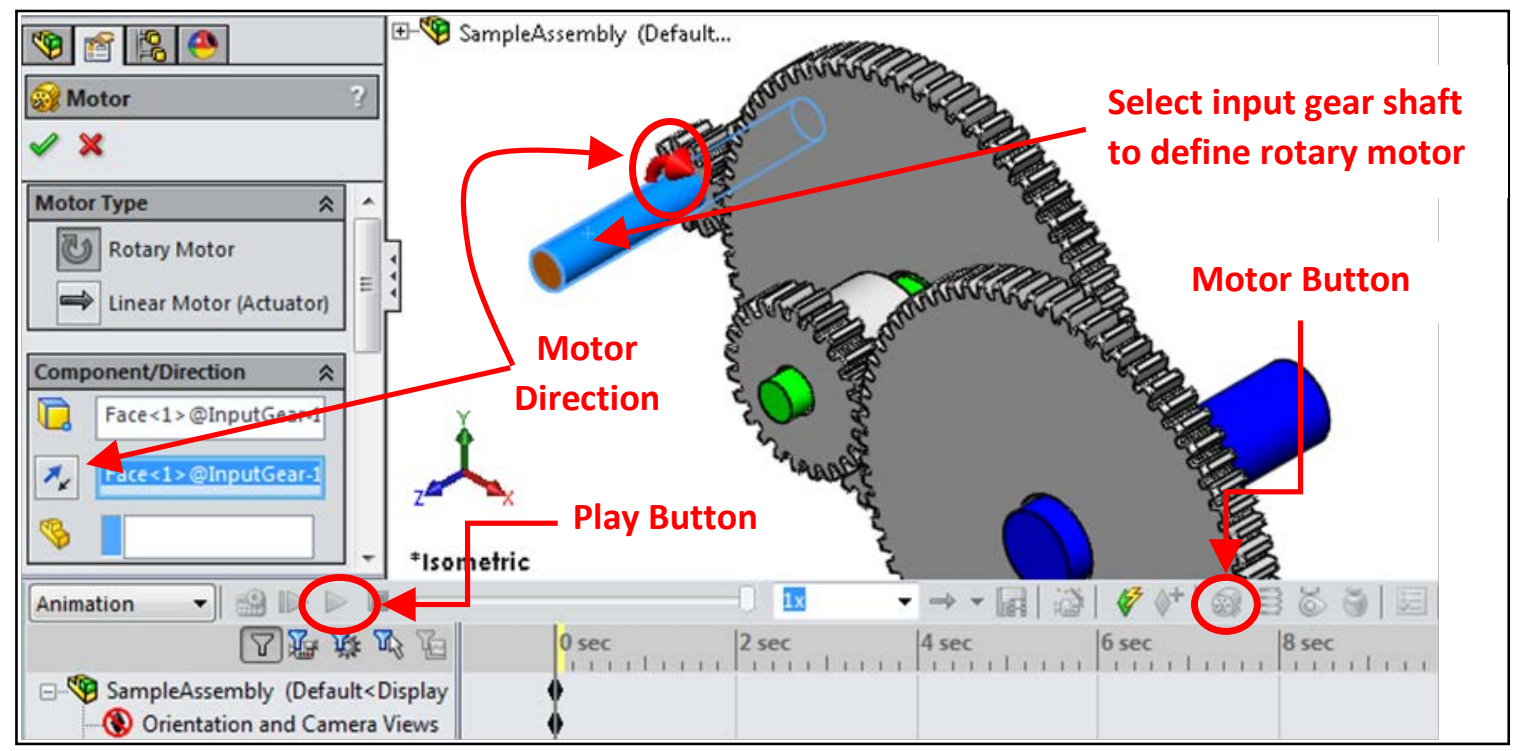

Figure 4. Definition of a motor in SolidWorks. 
The students were given the steps to create the 3D assembly model in SolidWorks CAD software as well as the steps to setup and run a kinematic simulation to verify their results (see Figures 3 and 4).

\section{Methods}

The total enrollment for the Spring 2017 semester was 221 students and five lab sections capped at 48 students were offered. As described by Rios and Fadda, each week students have a 50 minute lecture and a 1 hour and 40 minute lab [7]. Students worked in groups of two and those sections with an odd number of students had one group of three. One faculty and two Graduate Teaching Assistants (GTAs) attended each lab section while the lecture was administered by one faculty and the GTAs were used for keeping track of attendance. In total, the large lecture and the five labs were supported by two full-time, non-tenure track faculty each assigned half of their teaching load for this course, two full-time GTAs, and one half-time GTA.

In the of Fall 2017, a single lecture/lab was offered and aided by one non-tenure track faculty (one-quarter teaching load), one GTA and one upper-level Undergraduate Student (UGS). The students responded well to the UGS and in future semesters we will incorporate more UGS into the labs. It should be noted that due to the course schedule of UGSs, it may be more difficult to match them to the lab schedules. However, our experience thus far has been that UGSs are reliable and eager to help. GTAs will be assigned grading responsibilities in addition to attending lecture/lab and office hours while the UGSs will be primarily used to support the labs and hold office hours.

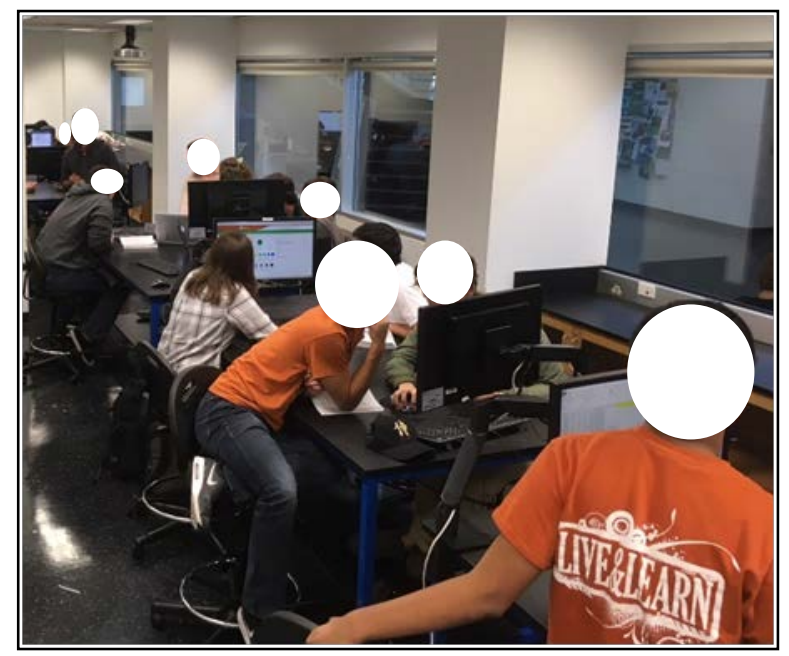

Figure 5. Students working in the lab.

Our experience has been that having the GTAs and UGS continually move around during the lab and stop to offer help makes the students more willing to ask questions.

This activity was administered in the Mechanical Engineering Freshman Studio (see Figure 5). This space is dedicated to supporting the first- and second-semester, first-year mechanical 
engineering labs. As aforementioned, this space supports a maximum of 48 students and has 12 large work tables equipped with two computers (thin clients) and one toolbox per table. Each table allows two groups of two students. This space is designated as a dry lab and there is a 3D printer. Office hours are held every day in the freshman studio and this space is available to students daily from early morning to late night. This activity required one computer per each group of two students equipped with 3D CAD software. As mentioned in Section 2, SolidWorks was the CAD software implemented but it should be noted that the assembly model and simulation can be created in any 3D CAD software.

Students were asked to provide anonymous feedback on the activity in a survey administered at the end of the course. The survey includes the student's perception of their understanding of activity topics, the value of the activity for their future education, motivation, and their enjoyment of the activity. Specifically, the students were asked to respond to the following statements based on a 5-point Likert scale where a value of 1 meant they strongly disagreed and a value of 5 meant that they strongly agreed with the statement.

1. This activity helped me better understand aspects of the design process including motion analysis of simple transmissions and design under constraints.

2. After working on this activity, I understand simple concepts related to machine components including angular velocity, power transmission, velocity ratios, pitch of a spur gear, simple and compound gear trains.

3. Searching for components in a catalog to satisfy design requirements was a valuable activity.

4. Using SolidWorks to create a motion simulation was a valuable experience.

5. After working on this activity, I feel more confident using SolidWorks.

6. I was motivated to complete the activity.

7. I enjoyed working on the activity.

8. The concepts I learned while working on this activity will be of value to me in other engineering courses.

The results for these statements are presented in the next section.

\section{Results}

Overall, the activity was successfully implemented and the students responded to it well. Some students required some additional time, which was provided with extended office hours. In future implementations, the number of labs dedicated to this activity will be increased from 2 to 3 . To successfully complete this activity within the proposed three lab periods, students should: (1) set up the equation, select gears, and download their respective models from the catalog during first lab period; (2) start the assembly model during the second lab period; and, (3) complete the assembly model and run the simulation during the third lab period. During the first lab period, students should be encouraged to discuss their calculations and gear selections with the faculty instructor or student helpers to ensure their gear selections satisfy the design requirements. 
The results for these statements are plotted in a diverging staked bar chart as shown in Figure 6. The raw data is given in Table 1. The course was taken by 221 students in the Spring 2017 semester and 143 students allowed their anonymous responses to be used for research purposes (65\% response rate). Students who completed the survey were awarded bonus points going toward their final exam and these bonus points were awarded whether or not they allowed their responses to be used for research purposes.

As can be seen from Figure 6, over $71 \%$ of the students who responded to the survey either agreed (A) or strongly agreed (SA) with each of the statements. This indicates that the students not only thought the activity was a valuable learning experience but enjoyed it as well. Engineering reports and 3D models provided by the students indicated that they were able to understand the design problem and how to use the kinematic equation to search for a valid set of gears to produce the required output speed.

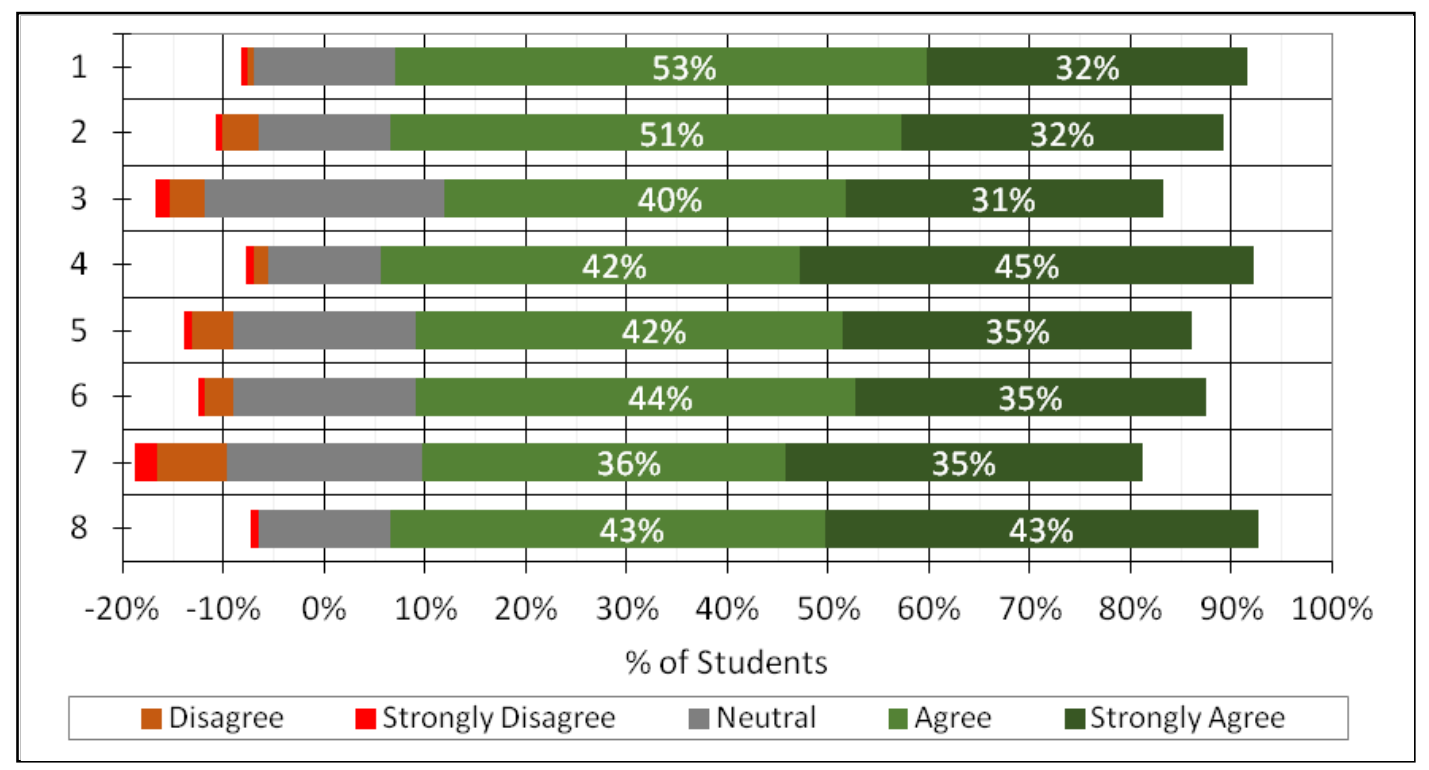

Figure 6. Student responses to survey questions.

In the survey students were asked to identify themselves as 'Female,' 'Male,' or 'Choose Not To Answer.' For this survey, 24 identified themselves as female (17\% of respondents), 117 as male (83\%), and 2 students chose not to answer (these students were omitted from results). The enrollment for the course was 33 female students (15\% of class) and 188 male students (85\%). Hence, the response rate of students identifying themselves as female and male is similar to the number of female and male students who completed the course.

Figure 7 shows the student responses separated by gender. The results for those who chose not identify their gender are not shown in this figure but they are provided in the raw data of Table 1. From this figure, we see that females and males provided similar responses to statements 1, 2, 4, 6 , and 8. Both genders felt the activity helped them understand concepts related to the design 
process and machine components, were motivated to complete the activity, and felt the concepts learned with this activity would be valuable in other engineering courses. We also see that there was a difference between the genders for statements 3, 5, and 7. Female students responded less positively regarding the value of searching for components in catalogs, improved confidence using SolidWorks, and enjoyment of working on the activity as compared to the male students. It would be helpful in future semesters to more clearly emphasize an everyday application for the mechanism such as the aforementioned loading tray for a Blu-ray player as suggested by Nilsson [14]. This will give a better sense of purpose to the work the students are asked to perform.

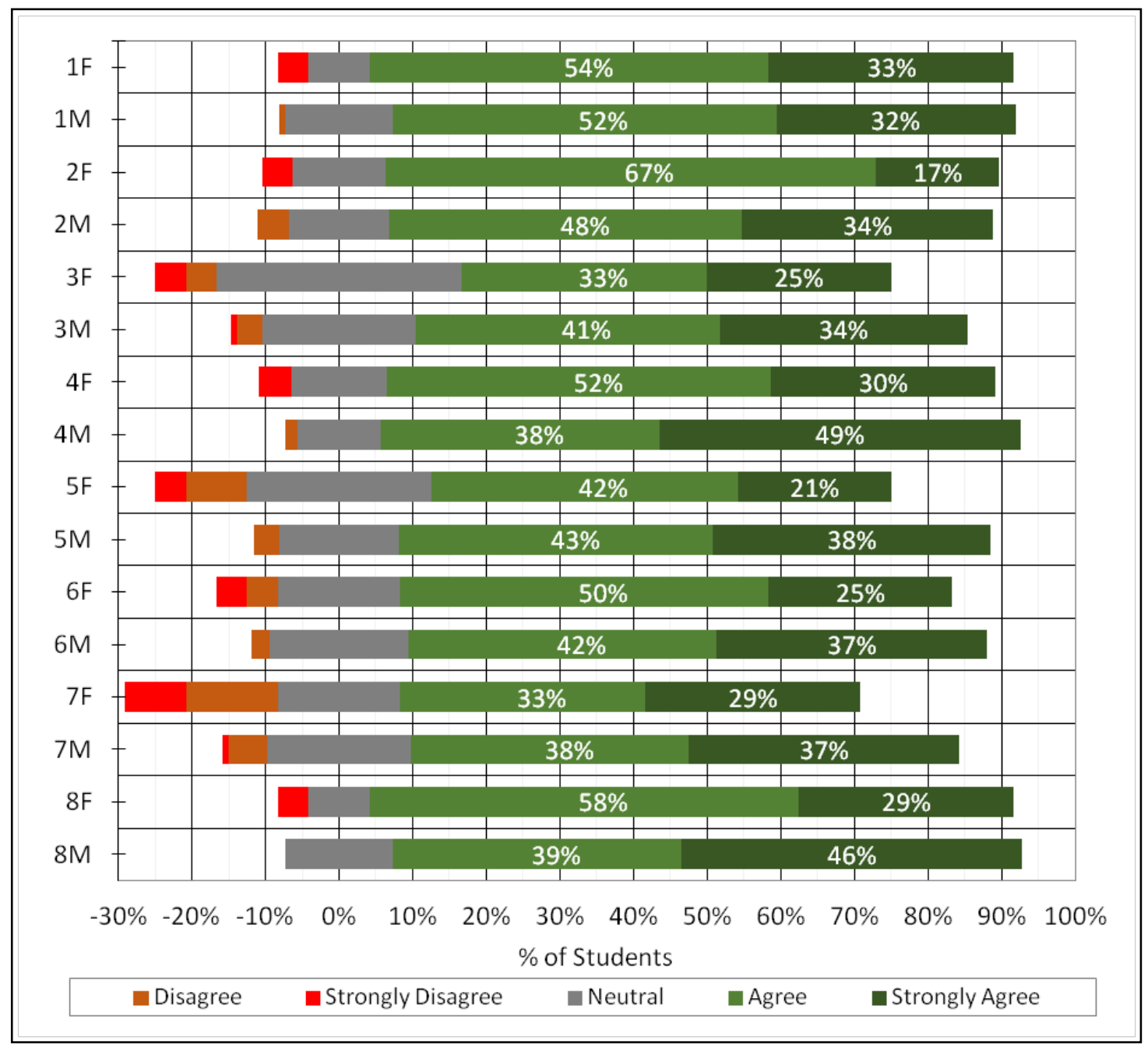

Figure 7. Student responses to survey questions separated by females (F) and males (M).

It should be noted that students were allowed to choose their teammate to work on this activity. Students who did not self-enroll into a group were randomly added to a group.

Students were also asked to provide free-response comments on any issues they faced and how to make improvements to the activity. Some students wrote: "it's a good introductory activity into simulations in solidworks," "it allows students to become more independent by selecting their 
own components for their projects," and "looking for different gears and comparing their physical properties and prices was a great learning experience." Some students wanted to go further with the project (beyond an introductory level course): "I feel there should be more emphasis on the CAD procedures for designing the gears," and "it may be beyond the scope of this class, but it would be more interesting to design a unique gear system." Another student wrote: "really interesting way to take what we learned in [CAD activity] to the next level." On the other hand, some students could have benefited from more lab time: "this was the most time consuming lab," and "need to make the lab time a little longer to learn all the concepts of the gears." To this end, as was previously mentioned the number of labs will be increased.

Table 1. Number of students who strongly disagree (SD), disagree (D), agree (A), strongly agree (SA) and where neutral $(\mathrm{N})$ with the statements. In the cells, the first value is 'Female,' the second 'Male,' and third is 'Choose Not To Answer.'

\begin{tabular}{|c|c|c|c|c|c|c|}
\hline Statement & SD & $\mathbf{D}$ & $\mathbf{N}$ & $\mathbf{A}$ & $\mathbf{S A}$ & Total \\
\hline 1 & $1 / 0 / 0$ & $0 / 1 / 0$ & $2 / 17 / 1$ & $13 / 61 / 1$ & $8 / 38 / 0$ & 143 \\
\hline 2 & $1 / 0 / 0$ & $0 / 5 / 0$ & $3 / 16 / 0$ & $16 / 56 / 1$ & $4 / 40 / 1$ & 143 \\
\hline 3 & $1 / 1 / 0$ & $1 / 4 / 0$ & $8 / 24 / 2$ & $8 / 48 / 0$ & $6 / 39 / 0$ & 142 \\
\hline 4 & $1 / 0 / 0$ & $0 / 2 / 0$ & $3 / 13 / 0$ & $12 / 44 / 2$ & $7 / 57 / 0$ & 141 \\
\hline 5 & $1 / 0 / 0$ & $2 / 4 / 0$ & $6 / 19 / 1$ & $10 / 50 / 1$ & $5 / 44 / 0$ & 143 \\
\hline 6 & $1 / 0 / 0$ & $1 / 3 / 0$ & $4 / 22 / 0$ & $12 / 49 / 2$ & $6 / 43 / 0$ & 143 \\
\hline 7 & $2 / 1 / 0$ & $3 / 6 / 1$ & $4 / 23 / 1$ & $8 / 44 / 0$ & $7 / 43 / 0$ & 143 \\
\hline 8 & $1 / 0 / 0$ & $0 / 0 / 0$ & $2 / 17 / 0$ & $14 / 46 / 2$ & $7 / 54 / 0$ & 143 \\
\hline
\end{tabular}

\section{Conclusions}

In this paper, a conceptual mechanism design activity for a freshman mechanical engineering course was described. The resources to administer this activity were also presented. The activity was successfully administered to 221 students. Results from a student survey (143 respondents) indicate the activity was well received by the students. Engineering reports and 3D models submitted by the students also indicated a high-level of understanding of the concepts. Overall, the activity was successful in introducing concepts of motion and power transmission to the students.

Examining the responses by gender, we see female and male students responded similarly to a majority of the statements. However, female students responded less positively to three statements related to value of searching for components in catalogs, confidence using SolidWorks, and enjoyment of working on the activity as compared to the male students. It would be helpful in future semesters to more clearly emphasize an everyday application for the mechanism as this will give a better sense of purpose to the work the students are asked to perform.

\section{References}

[1] Bates, J. S., "A First Year Course Based on Conceptual Design," Proceedings of the ASEE Annual Conference and Exposition, Indianapolis, Indiana, 2014. 
[2] Ambrose, S. A., Amon, C. H., "Systematic Design of a First-Year Mechanical Engineering Course at Carnegie Mellon University," Journal of Engineering Education, Vol. 86(2), 1997.

[3] Pendergrass, N. A., Kowalczyk, R. E., Dowd, J. P., Laoulache, R. N., Nelles, W., Golen, J. A., Fowler, E., "Improving First-Year Engineering Education*," Journal of Engineering Education, Vol. 90(1), 2001.

[4] Dym, C. L., Agogino, A. M., Eris, O., Frey, D. D., Leifer, L. J., "Engineering Design Thinking, Teaching, and Learning," Journal of Engineering Education, Vol. 94(1), 2005. [5] Marra, R. M., Palmer, B., Litzinger, T. A., "The Effects of a First-Year Engineering Design Course on Student Intellectual Development as Measured by the Perry Scheme," Journal of Engineering Education, Vol. 89(1), 2000.

[6] Knight, D. W., Carlson, L. E., Sullivan, J., "Improving Engineering Student Retention Through Hands-On, Team Based, First-Year Design Projects," Proceedings of the International Conference on Research in Engineering Education, 2007.

[7] Rios, O. and Fadda, D., "A Mechanical Engineering Activity-Based Freshman Course," Proceedings of the ASME IMECE, Tampa, Florida, 2017.

[8] Rios, O. and Fadda, D., "A First-Year Design-Based Activity for Mechanical Engineering Students," Proceedings of the ASEE Gulf-Southwest Section Annual Conference, University of Texas at Dallas, Richardson, Texas, 2017.

[9] Fadda, D. and Rios, O., "Designing a Scalable Statics Project for a First-Year Mechanical Engineering Course," First Year Engineering Experience (FYEE) Conference, Daytona Beach, Florida, 2017.

[10] Fadda, D. and Rios, O., "Heat Transfer Activity for a First-Year Mechanical Engineering Course," Proceedings of the ASEE Gulf-Southwest Section Annual Conference, University of Texas at Austin, Austin, Texas, 2018.

[11] Rios, O. and Fadda, D., "A Conceptual Mechanism Design Activity for an Introduction to Mechanical Engineering Course,” Proceedings of the ASEE Gulf-Southwest Section Annual Conference, University of Texas at Austin, Austin, Texas, 2018.

[12] Wickert, J., Lewis, K., "An Introduction to Mechanical Engineering," Fourth Edition, Cengage Learning, ISBN 978-305-63513-5, 2015.

[13] McMaster-Carr Supply Company (US), Online Catalog, www.mcmaster.com, 2017. [14] Nilsson, T. L., "Why Am I Learning This? Using Everyday Examples in Engineering to Engage Female (and Male) Students in the Classroom," Proceedings of the ASEE Annual Conference and Exposition, Indianapolis, Indiana, 2014. 